\title{
Psychological impact of an epidemic/ pandemic on the mental health of healthcare professionals: a rapid review
}

Suzannah Stuijfzand ${ }^{1}$, Camille Deforges ${ }^{1}$, Vania Sandoz ${ }^{1}$, Consuela-Thais Sajin ${ }^{1}$, Cecile Jaques ${ }^{2}$, Jolanda Elmers ${ }^{2}$ and Antje Horsch ${ }^{1,3^{*}}$ (D)

\begin{abstract}
Background: Epidemics or pandemics, such as the current Coronavirus Disease 2019 (COVID-19) crisis, pose unique challenges to healthcare professionals (HCPs). Caring for patients during an epidemic/pandemic may impact negatively on the mental health of HCPs. There is a lack of evidence-based advice on what would be effective in mitigating this impact. Objectives: This rapid review synthesizes the evidence on the psychological impact of pandemics/epidemics on the mental health of HCPs, what factors predict this impact, and the evidence of prevention/intervention strategies to reduce this impact.
\end{abstract}

Method: According to rapid review guidelines, systematic searches were carried out in Embase.com, PubMed, APA PsycINFO-Ovid SP, and Web of Science (core collection). Searches were restricted to the years 2003 or later to ensure inclusion of the most recent epidemic/pandemics, such as Severe Acute Respiratory Syndrome (SARS). Papers written in French or English, published in peer-reviewed journals, and of quantitative design using validated measures of mental health outcomes were included. Of 1308 papers found, 50 were included. The full protocol for this rapid review was registered with Prospero (reg.no. CRD42020175985).

Results: Results show that exposed HCPs working with patients during an epidemic/pandemic are at heightened risk of mental health problems in the short and longer term, particularly: psychological distress, insomnia, alcohol/ drug misuse, and symptoms of posttraumatic stress disorder (PTSD), depression, anxiety, burnout, anger, and higher perceived stress. These mental health problems are predicted by organizational, social, personal, and psychological factors and may interfere with the quality of patient care. Few evidence-based early interventions exist so far.

Discussion: HCPs need to be provided with psychosocial support to protect their mental wellbeing if they are to continue to provide high quality patient care. Several recommendations relevant during and after an epidemic/ pandemic, such as COVID-19, and in preparation for a future outbreak, are proposed.

Keywords: Epidemic, Pandemic, COVID-19, Mental health, Healthcare professionals, Interventions, Review, Prevention, Intervention, Outbreak

\footnotetext{
* Correspondence: Antje.Horsch@chuv.ch

'Institute of Higher Education and Research in Healthcare (IUFRS), University of Lausanne, Route de la Corniche 10, 1010 Lausanne, Switzerland

${ }^{3}$ Department Woman-Mother-Child, Lausanne University Hospital, Avenue Pierre-Decker 2, 1011 Lausanne, Switzerland

Full list of author information is available at the end of the article
}

C C The Author(s). 2020 Open Access This article is licensed under a Creative Commons Attribution 4.0 International License, which permits use, sharing, adaptation, distribution and reproduction in any medium or format, as long as you give appropriate credit to the original author(s) and the source, provide a link to the Creative Commons licence, and indicate if changes were made. The images or other third party material in this article are included in the article's Creative Commons licence, unless indicated otherwise in a credit line to the material. If material is not included in the article's Creative Commons licence and your intended use is not permitted by statutory regulation or exceeds the permitted use, you will need to obtain permission directly from the copyright holder. To view a copy of this licence, visit http://creativecommons.org/licenses/by/4.0/. The Creative Commons Public Domain Dedication waiver (http://creativecommons.org/publicdomain/zero/1.0/) applies to the data made available in this article, unless otherwise stated in a credit line to the data. 


\section{Background}

Epidemics or pandemics, such as the current COVID-19 crisis, pose a significant threat to public health. This sudden outbreak of a novel, highly contagious disease, is unpredictable and associated with high morbidity and mortality rates [1]. An epidemic (or outbreak) is the "occurrence in a community or region of cases of an illness ... clearly in excess of normal expectancy" [2] , p. 3, and a pandemic (or large scale outbreak) is "a large epidemic", "best reserved for infectious diseases." [3] , p.1020. Compared to other large-scale disasters, epidemics/pandemics pose unique challenges to HCPs, as the treatment course is often yet unknown, social isolation is required following presentation of first symptoms, and frontline HCPs not only fear for the safety of their patients, but also for their own health, and that of their close family members. Furthermore, many HCPs are suddenly required to carry out unfamiliar tasks in an unfamiliar area of care, such as high-risk, high-intensity units, all of which are likely to be associated with elevated levels of psychological distress [4]. These characteristics of an outbreak reduce the availability of social support, including support from their colleagues and their family, which is known to buffer the negative impact of stress [4].

\section{Why is this review needed?}

Caring for patients during an epidemic/pandemic may impact negatively on the mental health of HCPs $[5,6]$. While studies on this impact exist, this literature has yet to be updated and fully synthesized alongside a review of potential risk and protective factors. Understanding this mental health impact would sensitize policy makers and governance bodies about the importance of considering the mental health needs of HCPs in the preparations for, during, and in the aftermath of such outbreaks. Furthermore, there is a lack of evidence-based advice on what would be effective in mitigating this impact, calling for a synthesis of the evidence on prevention/intervention strategies.

We therefore conducted a rapid review on the psychological impact of pandemics/epidemics on the mental health of HCPs, what factors may protect or increase the risk of this impact and what evidence there is for prevention/intervention strategies to reduce this impact.

\section{Methods}

The full protocol for this rapid review was registered with Prospero (reg.no. CRD42020175985). A rapid review is defined as a form of synthesis that streamlines or omits methods for a systematic review in order to produce evidence for stakeholders [7]. Therefore, the number of reviewers conducting each phase of the screening differed from that of a traditional systematic review and no formal study quality evaluation took place (see C Garritty, G Gartlehner, C Kamel, V King, B Nussbaumer-Streit, A Stevens, C Hamel and L Affengruber [7] for guidelines). However, a rapid review was deemed the method of choice in order to support decision makers in a timely manner on how the mental health of their HCPs during the current COVID-19 crisis can be protected.

\section{Search strategy and selection criteria}

Following rapid review guidelines C Garritty, G Gartlehner, C Kamel, V King, B Nussbaumer-Streit, A Stevens, C Hamel and L Affengruber [7], systematic searches were carried out on the 22nd March 2020 on the databases Embase.com, PubMed, APA PsycINFO - Ovid SP, Web of Science (core collection). An additional search was performed in Google Scholar, followed by citation tracking of included studies. Searches were restricted to the years 2003 or later, ensuring inclusion of the most recent epidemic/pandemics, such as SARS. The search was based on a combination of terms related to "healthcare professional" (e.g., "healthcare provider"), "disease outbreak" (e.g., "pandemic") and "mental health" (e.g., "depression"). It included (but was not limited to) the following epidemics/pandemics that occurred from 2003 onwards: COVID-19, severe acute respiratory syndrome (SARS), Middle East respiratory syndrome (MERS), influenza pandemic (H1N1), avian influenza (H5N1), and West Nile Fever (see Supplementary Materials: Additional file 1 for the full search algorithms).

For inclusion, papers had to be written in French or English, published in peer-reviewed journals, and present quantitative data including validated measures of mental health outcomes. Measures were judged to be valid if there was psychometric information available confirming their validity and reliability. Modified versions of validated measures were accepted if the modification entailed adapted instructions for a specific scenario/ trauma/population. Intervention studies were included if the design allowed the assessment of the effectiveness of the intervention on mental health outcomes. Studies were included when HCPs worked directly with infected/suspected patients in hospitals or in communities during the outbreak (exposed). Mixed methods studies were included if quantitative data could be separated from qualitative date. Studies did not have to contain a control group for inclusion. Conference abstracts, opinion pieces, editorials, and letters were excluded, as were (reviews of) qualitative studies. Titles, abstracts and then full texts were screened by two researchers. Where the researchers were unsure of eligibility, the paper was passed through to the next phase of screening to allow further scrutiny. For each accepted article after full-text screening, two researchers carried out data extraction at 
different times, and a third one checked for and resolved any discrepancies. All journals of accepted papers were verified as being peer-reviewed journals through Ulrich's Global Serials Directory, or on the website of the journal by a specialist librarian.

\section{Results}

Figure 1 depicts the screening and eligibility checking process and details the numbers of papers included and excluded at each phase, including reasons for exclusion for the full-text screening phase. As can be seen in Fig. 1, of 1308 papers found, 50 were included in this review. The characteristics of studies that met our inclusion criteria are presented in Table 1. Across the manuscript, as in Table 1, long-term effects are those reported in study as measured 6 months or longer after the outbreak.

From the included papers, two systematic reviews were identified that directly contributed to the research questions. One reviewed the evidence of the impact of past outbreaks on the mental health of HCPs [5] and one reviewed the evidence for organizational and social predictors of the impact of past outbreaks on the mental health of HCPS [6]. Therefore, a summary of these systematic reviews are a focal part of this rapid review. Of the 50 accepted papers for this rapid review, 21 were included in the review of Vyas et al. [5] and 16 were included in the review of Brooks et al. [6], ten appeared in both (see Table 1). Beyond the systematic reviews, data extracted from primary studies are included in this rapid review if they are more recent than the search dates of the systematic reviews, report on mental health outcomes not covered by the first systematic review, or investigated predictors of mental health outcomes not included in the second systematic review.

\section{The psychological impact of an epidemic/pandemic on the mental health of healthcare professionals}

A systematic review and meta-analysis [5] (including studies from 2000 to 2014) showed an impact of an epidemic/pandemic on the mental health of HCPs. This review included studies using both diagnostic tools and self-report measures with clinical cut-offs to assess

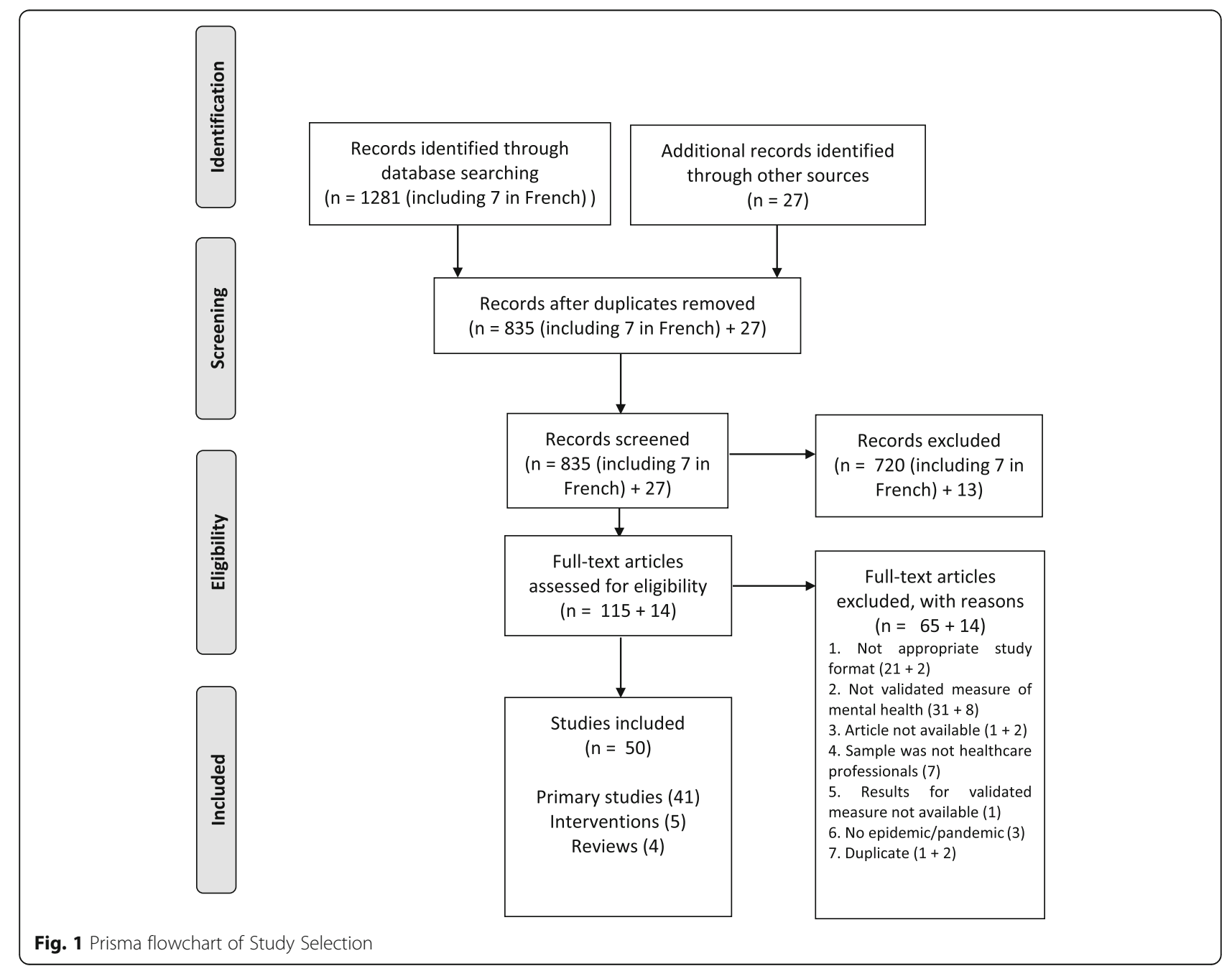




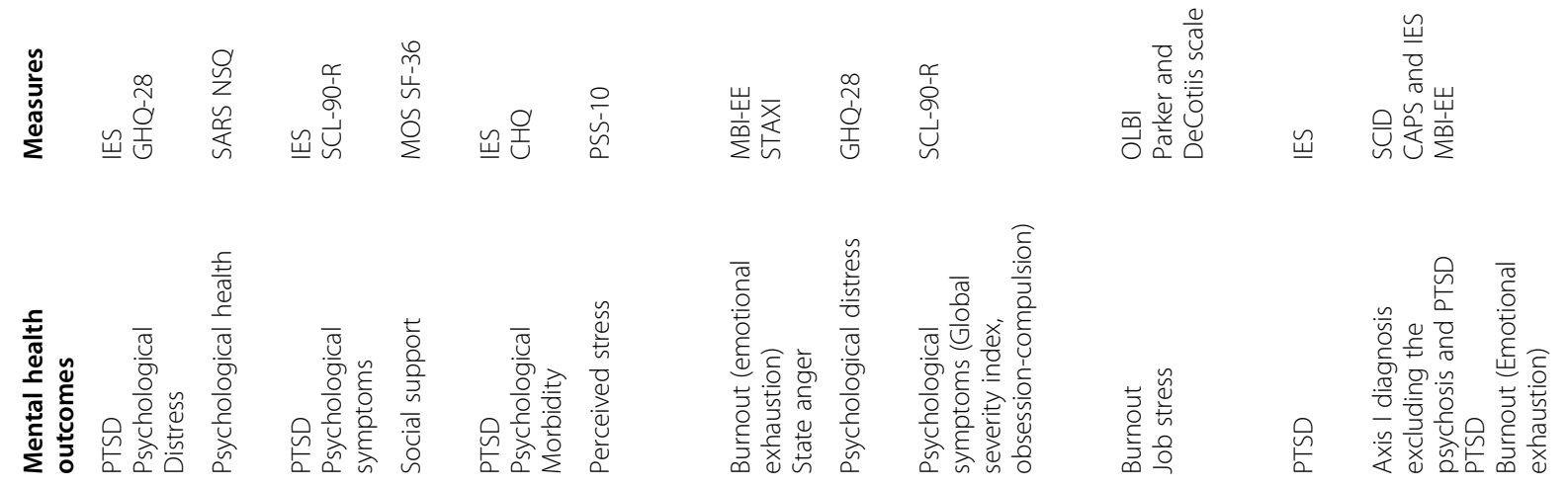

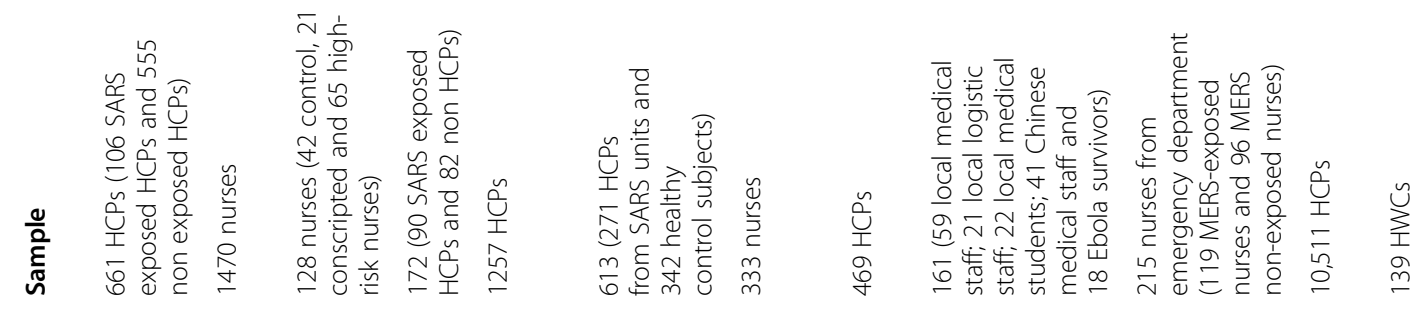

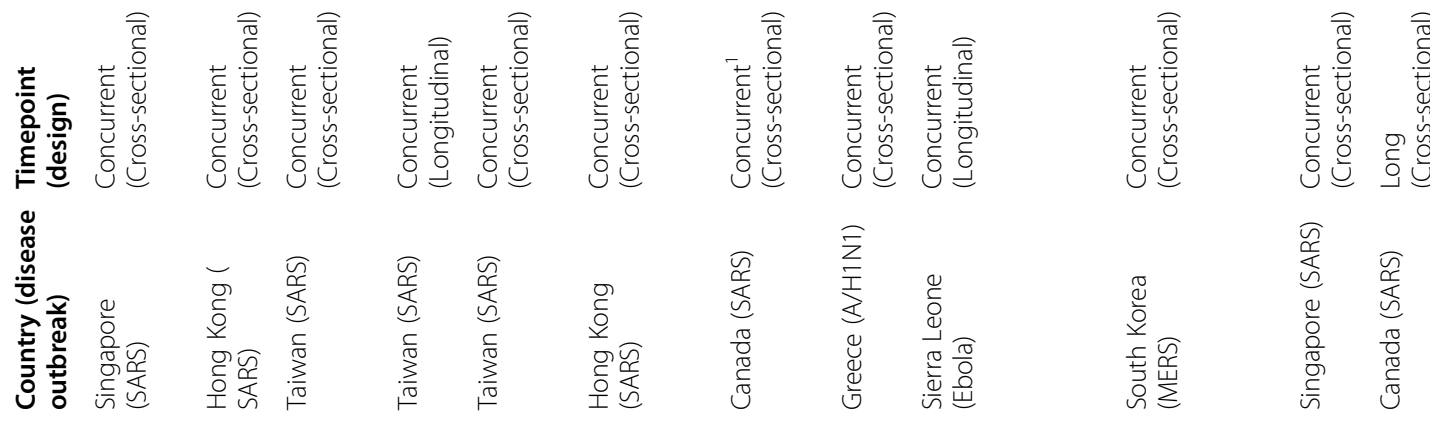

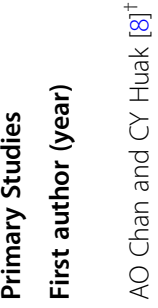

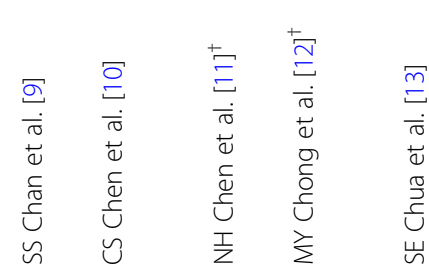

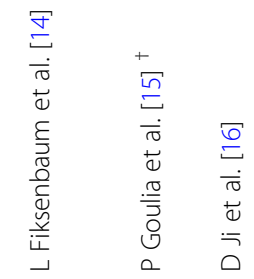

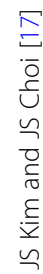

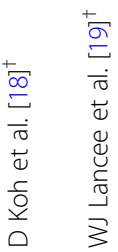




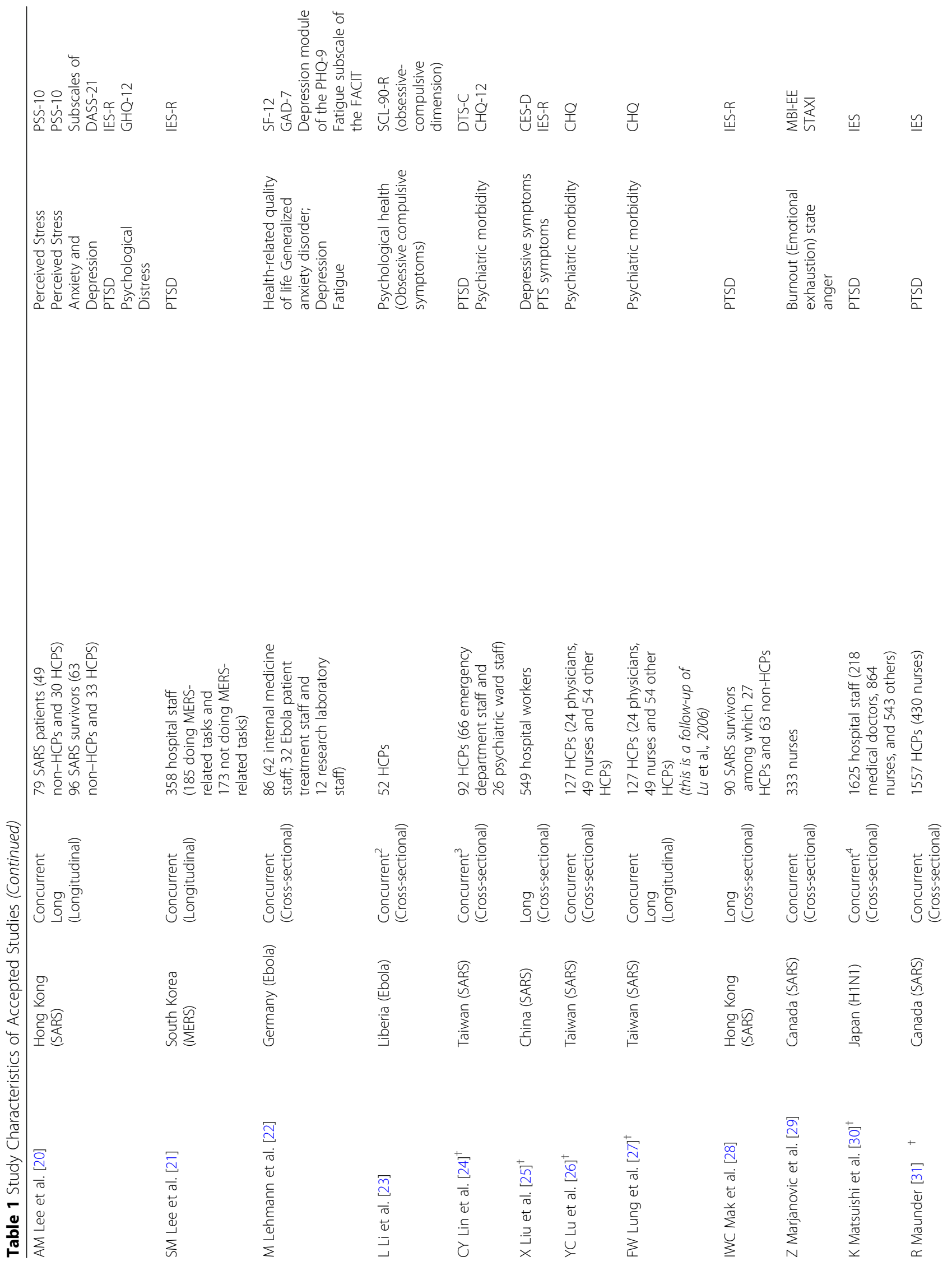




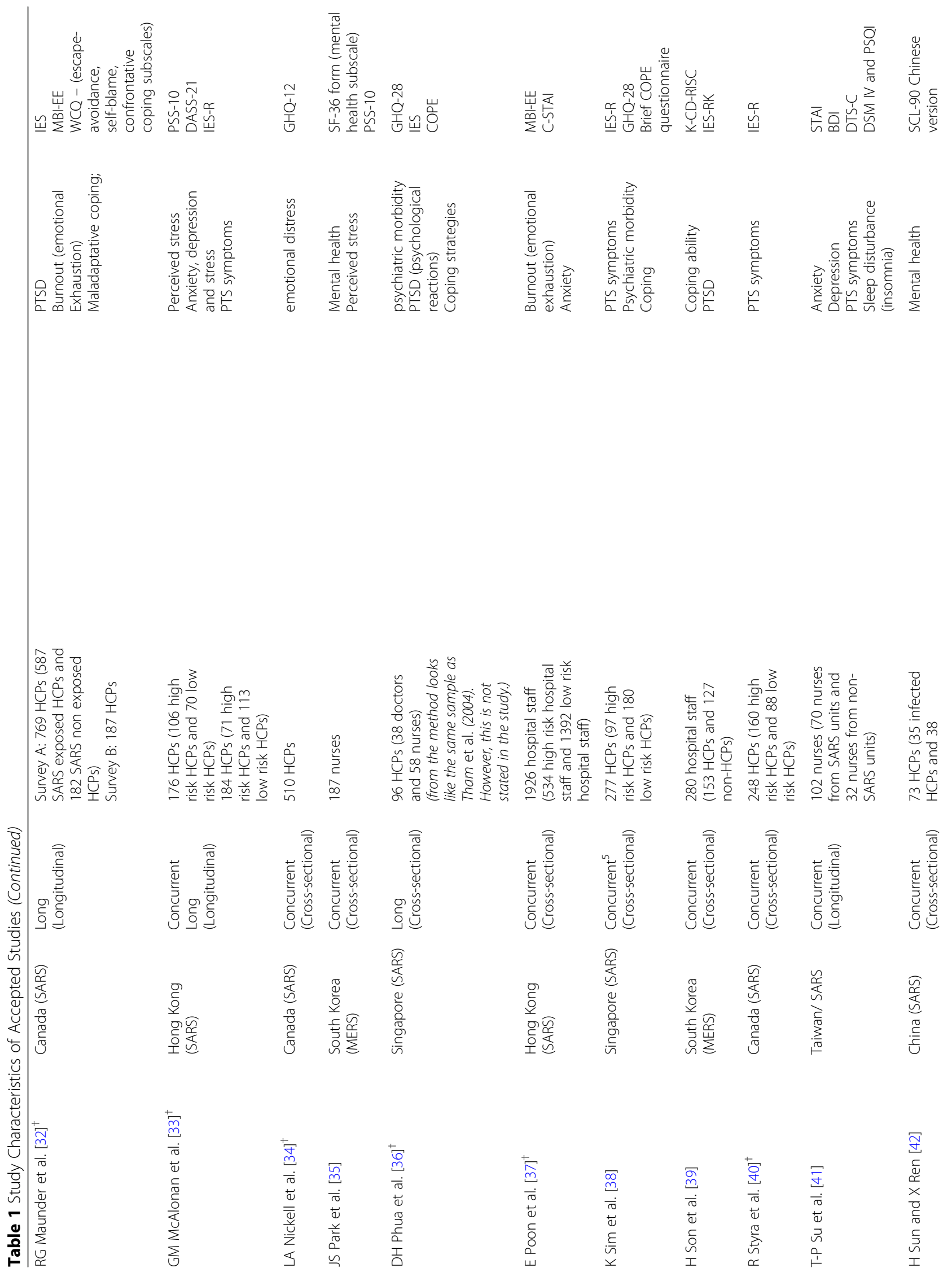




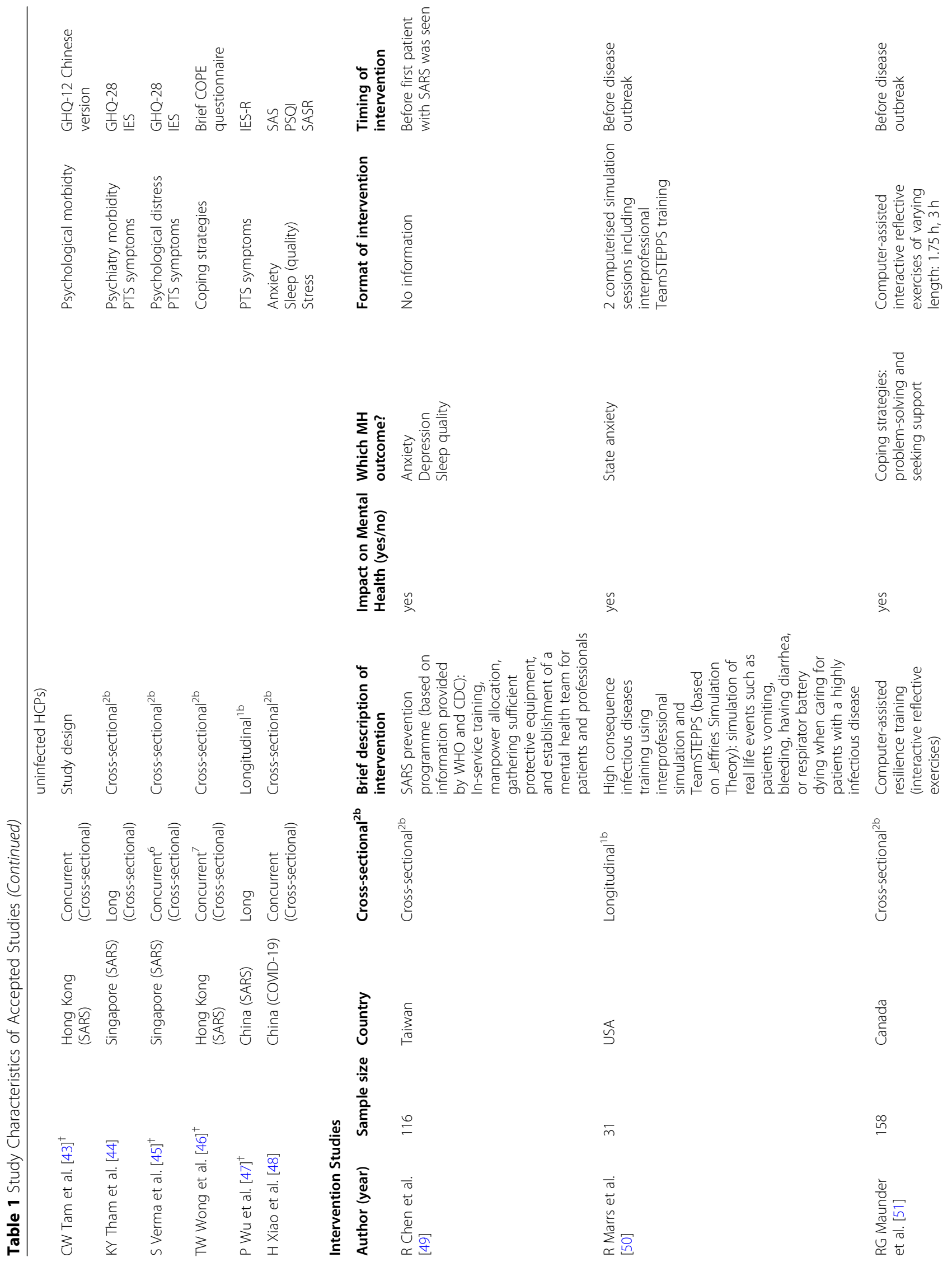




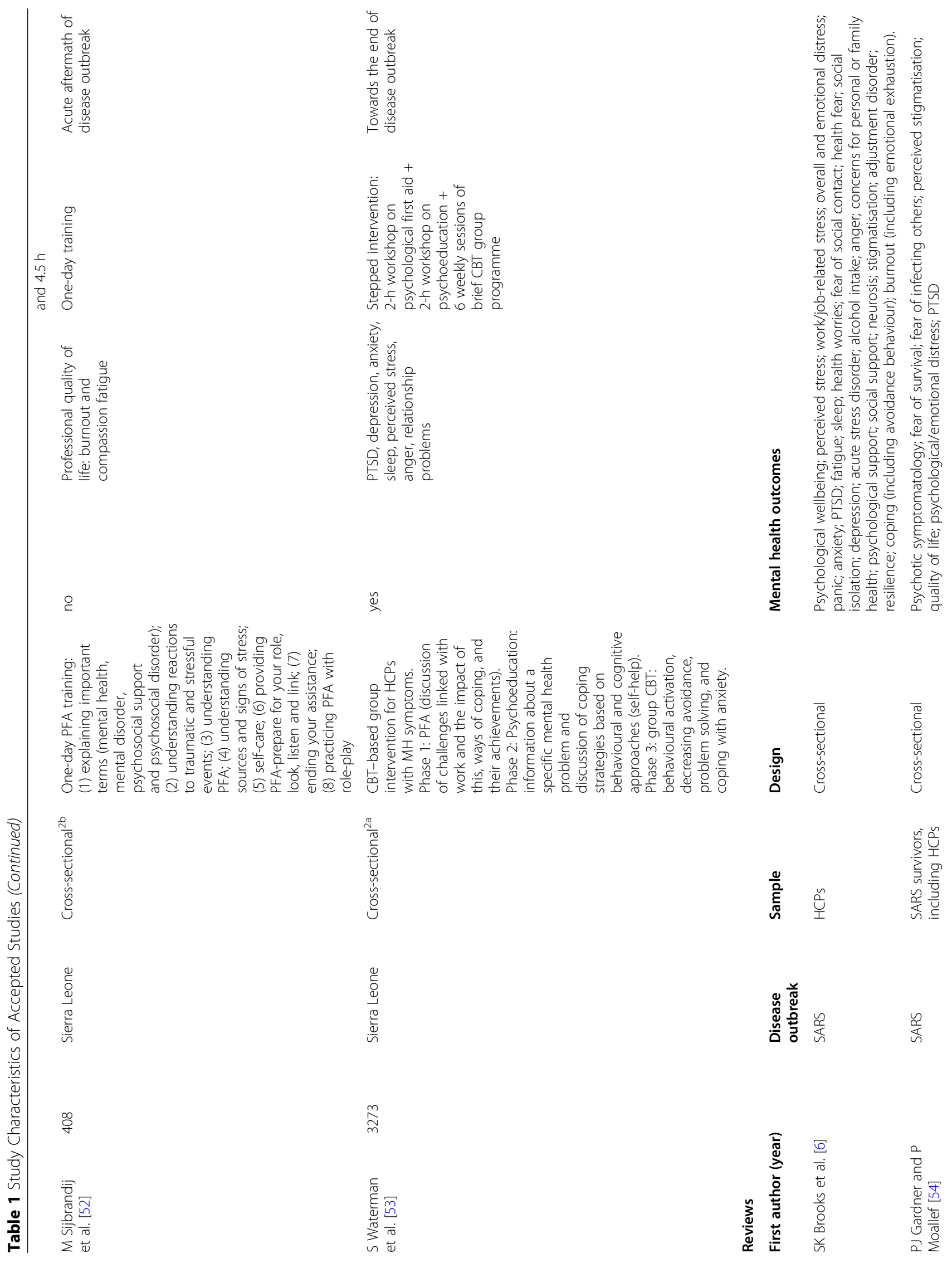




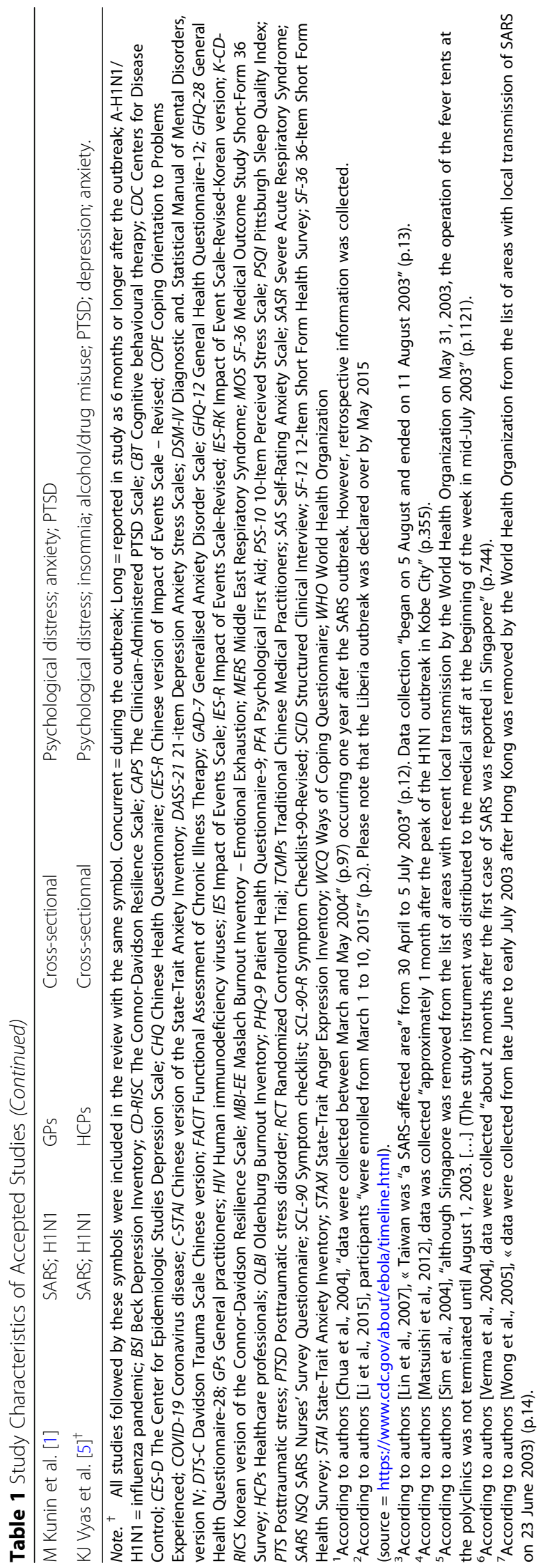


mental health outcomes. Therefore, percentage prevalence's are best interpreted as 'probable' percentage of cases. Effect sizes (standardised mean difference) reflect the difference between an exposed HCPs group and a control group. Thus, where a positive effect is reported, the exposed group showed higher symptom scores than the control group. In this review, psychological distress was assessed in 13 studies, with an average rate among exposed HCPs of approximately 40\% (range: 11-75\%). Insomnia was assessed in four studies, with an average rate among exposed HCPs of approximately 39\% (range: 30-52\%). Alcohol and drug misuse were assessed in five studies, with an average rate of approximately 13\% (range: 6-21\%). Posttraumatic stress disorder (PTSD) symptoms were assessed in 19 studies, with an average rate of approximately $21 \%$ (range: $10-33 \%$ ), of whom $40 \%$ reported persistently high PTSD symptoms 3 years after exposure. Meta-analytic results showed effects were small, (SMD $=0.12,95 \% \mathrm{CI}=-0.23$ to 0.47 ) but not significant. Depression symptoms were measured in eight studies, with an average rate of approximately $46 \%$ (range: 23-74\%), of whom up to 9\% reported severe levels. $11 \%$ were clinically diagnosed 1 month after the disease outbreak. Meta-analytic results showed effects were moderate $(\mathrm{SMD}=0.40,95 \% \mathrm{CI}=0.24-0.51)$ and significant. Anxiety symptoms were assessed in fourteen studies. The average rate was approximately $45 \%$ (range: 19-77\%). Meta-analytic results showed effects were small, (SMD $=0.08,95 \% \mathrm{CI}=-0.09$ to 0.25 ) and not significant.

Further mental health outcomes were reviewed that had not been included in Vyas et al. [5] or more recent papers (2015-2020) containing more data on the same outcomes. Table 2 contains all data related to the mentioned relationships. Burnout symptoms were assessed by five studies [14, 17, 29, 32, 37]. It should be noted that the sample of Z Marjanovic, ER Greenglass and S Coffey [29] is the same sample as L Fiksenbaum, Z Marjanovic, ER Greenglass and S Coffey [14]. Burnout symptoms during the outbreak were shown to be correlated with exposure [14], were significantly higher in HCPs exposed to the outbreak than in non-exposed HCPs [17, 37], and were predicted by exposure (vs non-exposure) [29]. The difference between exposed and non-exposed groups were significant over a year after the outbreak [32] and also impacted on HCPs' ability to work. Indeed, exposed HCPs were more likely than non-exposed HCPS to work reduced hours and have more sickness absence [32], but also to show avoidant behaviour toward patients [29]. Across these five studies, there is thus accumulating evidence of the impact of an epidemic/pandemic on burnout symptoms during the outbreak, with some evidence of a long-term effects, and detrimental patient care-related behaviours during and after the outbreak.
Two studies [14, 29] investigated state anger within the same sample. L Fiksenbaum, Z Marjanovic, ER Greenglass and S Coffey [14] showed that caring for infected patients was correlated with increased levels of state anger in HCPs during the outbreak. Z Marjanovic, ER Greenglass and S Coffey [29] found that exposure (vs non-exposure) did not predict state anger but the latter was correlated with avoidant behaviour towards patients during the outbreak. As results pertain to the same sample, evidence for an impact on state anger is weak.

Five studies [13, 20,33,35,48] investigated levels of perceived stress. Two studies found that during the outbreak, perceived stress levels of exposed HCPs were higher than a normative value $[13,33]$, whereas two studies showed perceived stress was no different between exposed and non-exposed HCPs [20, 33]. However, a year following the outbreak, perceived stress was higher amongst exposed vs non-exposed HCPs and had increased over time [33]. In addition, a year following the outbreak, perceived stress was higher amongst HCPs vs non-HCPs and had increased over time for HCPs only [20]. Evidence also indicates that during a pandemic, perceived stress was a mediator between social support and sleep quality [48] and between hardiness (resilience) and stigma, respectively, and mental health [35].

Two studies $[38,46]$ investigated coping strategies during an epidemic/pandemic. One showed that, during an outbreak, HCPs with psychiatric or PTSD symptoms used maladaptive coping strategies compared with those without symptoms [38]. It should be noted that there was no difference between exposed vs non-exposed HCPs on psychiatric or PTSD symptoms [38]. Furthermore, without a pre- outbreak measure, it is unclear whether all staff were equally affected and there is thus no evidence of the effect of the outbreak. However, the size of the non-exposed sample was double that of the exposed group, raising questions of power for that test. The second study showed that during an outbreak, different groups of HCPs used different coping strategies (see Table 2) [55]. Authors stated that the sample had been exposed to the infection; however, without a comparison group or 'pre-outbreak' measure, it is unclear whether the use of coping strategies was affected by the outbreak. These two studies suggest that during an outbreak, HCPs may engage in maladaptive coping strategies, however, it is unclear whether use of these strategies increased due to an outbreak.

One study [28] investigating the long-term effects of an outbreak on PTSD symptoms found that infected HCPs had significantly higher rates of chronic PTSD (30 months post SARS) than infected non-HCPs.

One further small study found that $2 \%$ of healthcare professionals with no psychiatric history before the 
Table 2 Table of results of accepted studies referred to in the manuscript, which provide evidence for the impact of pandemics/ epidemics on the mental health of healthcare professionals beyond the systematic review of KJ Vyas, EM Delaney, JA Webb-Murphy and SL Johnston [5]

\begin{tabular}{ll}
\hline First author (year) & Statistical approach \\
\hline SE Chua, et al. [13] & $\begin{array}{l}\text { Difference between HCPS and healthy controls } \\
\text { on stress levels (no inferential test) }\end{array}$ \\
Fiksenbaum et al. (2006) [14] & $\begin{array}{l}\text { Correlations between contact with SARS patients, } \\
\text { and emotional exhaustion and state anger. }\end{array}$ \\
D Ji, et al. [16] & $\begin{array}{l}\text { Difference in the psychological dimensions of the } \\
\text { SCL-90-R between 1 week after arrival of Chinese } \\
\text { medical staff in an outbreak zone (Sierre Leone) } \\
\text { and 1 week after withdrawal (either Man } \\
\text { Whitney U or t-test) }\end{array}$
\end{tabular}

JS Kim and JS Choi [17]

WJ Lancee et al. [19]

M Lehmann et al. [22]

IWC Mak et al., 2009. [28]

Z Marjanovic et al. [29]

RG Maunder, et al. [32]

GM McAlonan et al. [33]

JS Park et al. [35]
Group differences between MERS exposed vs not exposed nurses on MERS-related burnout (t-test)

Group differences between HCPs with vs. without history of mental illness on mental disorder development (Fischer test).

Group differences between internal medicine staff, Ebola patient treatment staff and research laboratory staff on anxiety levels (Test unspecified).

Group differences between infected HCPs and infected non HCPs on PTSD prevalence (Test unspecified).

Correlation between contact with SARS patients, and emotional exhaustion and state anger in nurses. Multiple regressions for emotional exhaustion and state anger.

Correlation between avoidance behavior, and emotional exhaustion and state anger.

Group differences between SARS exposed vs not exposed HCPs on burnout prevalence $\left(x^{2}\right)$. Group differences between SARS exposed vs not exposed HCPs on burnout (t-test or MannWhitney U Test)

Group differences between SARS exposed vs not exposed HCPs on face-to-face patient contact $\left(x^{2}\right)$.

Group differences between SARS exposed vs not exposed HCPs on work hours $\left(x^{2}\right)$.

During outbreak: Group differences between high vs low risk HCPs on perceived stress (t-test). Comparison of symptom scores to norm (no inferential test)

One year after outbreak: Group differences between high vs low risk HCPs on perceived stress (2-way ANOVA).

Interaction between time and infection level tested with a 2 way ANOVA.

Mediation analysis of the relationship between hardiness and mental health by perceived stress Mediation analysis of the relationship between
Results

Stress levels for HCPs $(M=18.6, S D=4.9)$ were similar to healthy control subjects $(M=18.3, S D=5.6)$, but $50 \%$ higher than the normative value for the PSS- 10 .

Exposure amongst nurses was significantly correlated with emotional exhaustion $(r=-.21 ; p<.001)$ and state anger $(r=-.18 ; p<.001)$.

Obsessive compulsion $(M=1.39, S D=.18$ vs $M=1.23$, $S D=.36 ; p=.1421)$; depression $(M=1.22, S D=.31$ vs $M=1.18, S D=.29 ; p=.5480)$; hostility $(M=1.09, S D=.13$ vs $M=1.09, S D=.18 ; p=1.00)$; paranoid ideation $(M=1.11, S D=.19$ vs $M=1.11, S D=.24 ; p=1.00)$ and psychoticism $(M=1.14, S D=.24$ vs $M=1.08, S D=.14$; $p=1.706)$.

Nurses exposed to infected/-suspected patients had higher MERS-related burnout scores $(M=3.09, S D=0.48)$ than non-exposed nurses $(M=2.93, S D=0.42, p=.013)$.

A year after the outbreak, HCPs with a history of mental illness before the outbreak had higher risk of developing a new mental DSM-IV axis 1 mental disorder (18\%), compared to healthcare workers without $(2 \%, p=.03)$.

Internal medicine staff, Ebola patient treatment staff and research laboratory staff did not significantly differ levels of anxiety.

Thirty months after SARS outbreak, PTSD prevalence was higher among infected HCPs (40.7\%) than among infected non HCPs $(19 \%, p=.031)$.

Contact with SARS patient was significantly correlated with emotional exhaustion $(r=-.21 ; p<.001)$ and state anger $(r=-.18 ; p<.001)$.

Contact with SARS patients significantly predicted emotional exhaustion $(\beta=-.15, p=.003)$ but did not predict state anger $(\beta=-.09, p=.068)$.

Avoidance behavior was significantly correlated with emotional exhaustion $(r=.26 ; p<.001)$ and state anger $(r=.33 ; p<.001)$.

Burnout prevalence is higher in exposed HCPs (30.4\%) than HCPS not exposed $(19.2, p=.003)$

Exposed HCPs had significantly higher burnout scores $(M d=19, I Q R=10-29)$ than non- exposed HCPs $(M d=16, I Q R=9-23)$

Since SARS outbreak, significantly less face-to-face patient contact was reported by exposed HCPs (16.5\%) compared to those who were not exposed $(8.3 \%, p=.007)$. Since SARS outbreak, significantly less work hours was reported by exposed HCPs (8.6\%) compared non exposed $\operatorname{HCPs}(2.2 \%, p=.003)$

Perceived stress levels did not significantly differ between high vs low risk HCPs $(t(164)=-1.36$, $p=0.176)$ although they were higher than the normative value (13).

Perceived stress levels of high-risk HCPs ( $M=18.6$, $S D=4.9$ ) were significantly higher than the low-risk HCPs $(M=14.8, S D=5, p<.05)$.

Change in perceived stress from 2003 to 2004 was significantly different for the 2 groups ( $F 1,336=4.61$, $P<0.05)$, with a general trend toward a decrease over time for low-risk HCPs and an increase for high-risk HCPs.

The relationship between hardiness and mental health was partially mediated by perceived stress (indirect effect 0.251, Boot SE $=0.638$ ). Where 
Table 2 Table of results of accepted studies referred to in the manuscript, which provide evidence for the impact of pandemics/ epidemics on the mental health of healthcare professionals beyond the systematic review of KJ Vyas, EM Delaney, JA Webb-Murphy and SL Johnston [5] (Continued)

\begin{tabular}{ll}
\hline First author (year) & Statistical approach \\
\hline & stigma and mental health by perceived stress
\end{tabular}

E Poon et al. [37]

K Sim et al. [38]

TW Wong et al. [46]

H Xiao et al. [48]
Group differences between hospital workers who had contact with SARS patients vs no contact with SARS patients on burnout symptoms (t-test).

Group differences between doctors and nurses with versus without psychiatric morbidities on effort coping, in context of SARS outbreak (Mann-Whitney U Test)

Group differences between doctors and nurses with versus without posttraumatic morbidities on effort coping, in context of SARS outbreak (Mann-Whitney U Test).

Group differences were examined between exposed and non exposed medical staff on psychiatric symptoms (Mann-Whitney test) and posttraumatic symptoms $\left(x^{2}\right)$, in the context of a SARS outbreak.

Group differences between doctors, nurses and healthcare assistants on coping strategies, in context of SARS outbreak (ANOVA with post hoc analyses).

\section{Results}

increased hardiness led to descrease stress $(B=-.31$,

$S E=.05, p<.001)$, which subsequently led to better mental health symptoms $(B=-.81, S E=.13, p<.001)$. The relationship between stigma and mental health was mediated by perceived stress (indirect effect $=-0.061$, Boot SE $=0.020)$. Where increased stigma led to increase stress $(B=.075, S E=.023$, $p=.002)$, which subsequently led to better mental health symptoms $(B=-.81, S E=.13, p<.001)$.

Hospital workers who had contact with SARS patients had significantly higher burnout symptoms $(M=7.3$, $S D=5.3$ ) than those who did not have contact with SARS patients $(M=5.1, S D=4.7, p<.001)$.

Doctors and nurses with psychiatric morbidities had higher scores on effort coping $(M=49.7, S D=13.2)$ than doctors and nurses without psychiatric morbidity $(M=39.7, S D=10.4, p<.001)$

Doctors and nurses with psychiatric morbidities had higher scores on effort coping $(M=53.4, S D=13.1)$ than doctors and nurses without psychiatric morbidity $(M=40.6, S D=10.9, p<.001)$. Exposed medical staff showed no difference to non-exposed staff in psychiatric symptoms $(M=2.6, S D=4.2$ vs. $M=2.3, S D=4.4, p=.28)$ or presence of posttraumatic symptoms (7.2\% vs.10.6\%, $p=.40$ ).

Planning was more likely to be used by doctors $(M=5.33, S D=1.44)$ compared to nurses $(M=4.85, S D=1.44, p<.05)$ and healthcare assistants $(M=4.42, S D=1.56$, $p<.01)$. Behavioral disengagement was more likely to be used by nurses $(M=2.96, S D=1.26)$ than doctors $(M=2.56, S D=0.91, p<.01)$. Self-distraction was more likely to be used by healthcare assistants $(M=4.58, S D=1.92)$ than doctors $(M=4.11, S D=1.42, p<.05)$.

The relationship between social support and sleep quality was mediated by perceived stress $(B=-.06, S E=.01, p=.002)$. Where a lack of social support $(B=.57, S E=.09, p<.001)$ led to an increase in perceived stress, which subsequently led to lower sleep quality $(B=.26, S E=.01, p<.001)$. outbreak had a new DSM-IV axis 1 mental disorder within 1 year after the outbreak [19]. Further research found no differences in symptoms of generalised anxiety disorder assessed during the outbreak between internal medicine staff, Ebola patient treatment staff, and research laboratory staff [22]. Another study found Chinese HCPs' symptoms of obsession-compulsion, depression, hostility, paranoid ideation, and psychoticism did not change from 1 week after arrival in an infected zone in Sierra Leone to 1 week after leaving. This may perhaps be explained by the fact that these HCPs were not in their own country and thus perhaps not subject to the same worries of going home and infecting families, as local staff [16]. Furthermore, when considering symptoms of obsessive compulsion, it should be noted that many of the behaviours considered symptoms may be 'normal' in times of an epidemic/pandemic, e.g., frequent washing of hands.

In conclusion, healthcare professionals exposed to working with patients during the COVID-19 outbreak may be at heightened risk of mental health problems, particularly, psychological distress, insomnia, alcohol/ drug misuse, and symptoms of PTSD, depression, anxiety, burnout, anger, higher perceived stress, and are more likely to engage in maladaptive coping strategies. 


\section{Predictors of psychological impact an of epidemic/ pandemic on the mental health of healthcare professionals}

The next section of this rapid review focuses on synthesizing the evidence on protective or risk factors with a view to informing recommendations for prevention and intervention. One systematic review synthesizing the social and occupational factors affecting the mental health of HCPs covered the literature up to 2015 and included 22 studies [6], all of which had investigated the SARS epidemic. SK Brooks, R Dunn, R Amlôt, GJ Rubin and N Greenberg [6] identified six organizational and four social factors as showing an influence on mental health outcomes. For this rapid review, no further evidence of social and organizational factors published after 2015 was identified amongst our accepted papers. Below is a brief summary of the organizational and social factors found by Brooks et al. [6] and associated data can be found in [6]. Further predictors, beyond organizational and social factors, may also influence the impact of epidemics/pandemics on mental health. Therefore, evidence for further protective and risk factors was extracted from other primary studies accepted for this rapid review. Thirteen papers were identified. Further predictors were classified as Psychological factors or Personal factors.

\section{Organizational predictors [6]}

Occupational role influenced mental health in HCPs, with those in direct contact with infected patients showing the poorest psychological outcomes. Nurses had poorer outcomes than doctors. Specialized training and preparedness showed as a protective factor against stress and anxiety. However, where training was perceived as inadequate, HCPs were more likely to experience symptoms of burnout and PTSD, and their symptoms often continued in the longer term. High-risk environments (i.e., a high risk of exposure to infected patients) were associated with higher symptoms of anxiety, stress, PTSD, alcohol consumption, burnout, and sleep problems. Being in quarantine was associated with higher symptoms of acute stress disorder, PTSD, and alcohol intake. The longer the quarantine, the greater an adverse effect was found on anger symptoms and avoidance behaviors.

Job stress, in particular where one's ability to do one's job was compromised, lack of control of one's job, and being involuntary deployed to work with infected patients negatively influenced mental health outcomes. For example, those who had to involuntarily care for infected patients reported higher levels of anxiety and depression symptoms than volunteers. Perceptions of safety threat and risk was identified as a protective and a risk factor for mental health. Feelings of trust in equipment and infection control procedures predicted lower emotional exhaustion and state anger. Belief in the precautionary measures within the workplace decreased concerns. However, high perception of personal risk predicted PTSD symptoms.

\section{Social predictors [6]}

In the context of an epidemic/pandemic, organizational support and family/friends support can function as protective factors when at adequate levels. However, low levels or inadequate organizational support, inclusive of psychological support and inadequate insurance/compensation, were risk factors for mental health. Social rejection or isolation was associated with poorer mental health outcomes. HCPs who experienced an impact on life (e.g., reduced contact with family) due to the outbreak showed greater mental health problems.

\section{Personal predictors}

Some personal characteristics were found to increase the risk of mental health problems of HCPs during an epidemic/pandemic. Those who were single were 1.4 times more likely to have minor psychiatric disorders according to a clinical cut-off $(95 \% C I=1.02-2.0, p=.048)$ during an outbreak. However, there was no test of whether this differed between exposed and non-exposed HCPs [8]. Being single was also found to be predictive of higher depressive symptoms $(A O R=4.35,95 \% \quad C I=$ $1.65-11.42 ; p=.0029)$ amongst hospital staff during an outbreak, though this test did not separate exposed from non-exposed HCPs [25]. Being single was also cited in the systematic review of [5] as being predictive of higher symptoms of psychological distress, higher depressive symptoms, and persistent PTSD symptoms. However, in one study by K Sim, PN Chong, YH Chan and WS Soon [38], being married was predictive of the presence of PTSD symptoms $(O R=11.43, C I=1.41$ to $100, p=.02)$. In another study, higher PTSD symptoms were found amongst those who lived in a dormitory or away from their family $(M=37.2, S D=20.2)$ than those living with family $(M=33.6 S D=19.5 .5 ; p<.005)$ [12]. During an outbreak, more nurses who perceived stress (50.7\%) additionally reported average or poor physical health than those who reported no stress $(18.4 \%, p=.001)$ [9]. Less healthcare work experience predicted higher psychological distress symptoms in exposed HCPs $(\beta=-.26$, $t=-3.28, p=.001$ ) [32]. Being a healthcare professional with a younger age [38] predicted the presence of PTSD symptoms during an outbreak $(O R=.94, C I=0.89$ to $0.98, p=.007)$. KJ Vyas, EM Delaney, JA Webb-Murphy and SL Johnston [5] in their systematic review also identified a younger age as predictive of symptoms of anxiety, depression and PTSD, and identified less healthcare experience as a predictor of symptoms of psychological distress, and PTSD. KJ Vyas, EM Delaney, JA Webb- 
Murphy and SL Johnston [5] also reported that HCPs with a lower household income reported higher PTSD symptoms during an outbreak. Finally, experiencing stigma (social rejection, prejudice, or discrimination due to their work) as HCPs during the outbreak predicted concurrent mental health symptoms $(\beta=-0.306, t=-$ $7.2376, p<0.001)$. This relationship was found to be mediated by perceived stress (indirect effect $=-0.061$, Boot $\mathrm{SE}=0.020)$ [35].

\section{Psychological predictors}

Resilience (hardiness) is a potential protective factor and was found to have both a direct and an indirect influence on mental health during an outbreak [35]. A higher resilience score directly predicted better mental health in exposed HCPs $(\beta=0.49, t=4.87, \quad p<0.001)$. Indirectly, hardiness, was associated with decreased stress perception, and this in turn was associated with better mental health (indirect effect $=0.251$, Boot SE $=0.638$ ) [35]. Maladaptive coping was a risk factor, with long-term predictive effects found on symptoms of burnout $(\beta=0.29, t=3.34, p=$ $0.001)$, PTSD $(\beta=0.31, t=3.78, p<0.001)$, and psychological distress $(\beta=0.37, t=4.39, p<0.001)$ [32]. Fatigue (physical and mental) predicted symptoms of poor mental $(B=-0.30, S E=0.12, p=.012)$ and physical $(B=-0.53$, $S E=0.11, p<.001)$ health during an outbreak, alongside perceived lack of knowledge of the infection [22]. Furthermore, having a negative emotional experience of the outbreak predicted an increased likelihood of PTSD amongst HCPs $(\beta=.17, p<.01)$. In this study, authors state negative emotional experience influenced PTSD symptoms of nonHCPs more than HCPs, while perceived risk (of infection) affected HCPs more than non-HCPs. However, how the statistical difference in magnitude of the coefficient was carried out was unclear [39]. More HCPs showing a new onset psychiatric disorder in the long term following an outbreak had a psychiatric disorder before the outbreak $(18 \%)$ than those without a new onset $(2 \% ; p=.03)$ [19].

Evidence for the psychological and personal factors identified in this review comes from one or two studies, suggesting preliminary rather than strong evidence. It is also not yet clear which of these factors is the most important. This preliminary evidence points towards identifying those at risk, who may benefit from prevention/ intervention programs, and what preventions/intervention may wish to target to influence mental health of HCPs.

What can be done to prevent or reduce the impact of an epidemic/pandemic on the mental health of healthcare professionals?

\section{Intervention programs}

Five studies [49-53] investigating the effect of preventative programs or interventions addressing mental health outcomes in HCPs were included (see Table 1 for more details about the content of the intervention and the study design). Regarding the preventative programs, the SARS prevention program addressed organizational, patient-care and psychological issues before HCPs saw the first infected patients and lead to an improvement in anxiety and depression symptoms, as well as sleep quality [49]. In another study, two computerised simulation sessions of real-life events linked to caring for infected patients resulted in lower state anxiety symptoms [50]. A pilot randomized controlled trial (RCT) testing varying lengths $(1.75 \mathrm{~h}, 3 \mathrm{~h}$ and $4.5 \mathrm{~h})$ of a computer-assisted resilience training (interactive reflective exercises) before the disease outbreak resulted in improved coping strategies (problem-solving and seeking support), with the medium length being optimal [51].

Regarding early intervention programs in the acute aftermath of the outbreak, a one-day psychological first aid training did not lead to improved professional quality of life (burnout and compassion fatigue) [52]. However, a stepped intervention introduced towards the end of the outbreak led to a decrease in symptoms of PTSD, depression, anxiety, anger, as well as perceived stress and relationship problems, and an improvement in sleep [53]. This early intervention program consisted firstly, of a two-hour workshop on psychological first aid, after which improvement in mental health symptoms was assessed. If individuals needed more, a two-hour workshop on psychoeducation was offered and again, improvement in their symptoms was evaluated. If more help was needed, then six weekly sessions of a brief cognitive behavioral therapy (CBT) group program were offered. Of note: HCPs were trained by mental health experts to carry out this stepped approach for their peers.

\section{Recommendations}

Please note that the following recommendations are based on the evidence of risk and protective factors, as well as intervention studies identified by this review. It is worth noting, that those based on risk and protective factors have not yet been tested for effectiveness.

Before the disease outbreak An infectious disease prevention program should be put into place by individual health services but coordinated at an international level. Important elements of the program are training of HCPs, planning and allocation of staff, provision of sufficient protective equipment, and establishment of a mental health team for professionals [49]. This may also include computerized simulation training of patient care during an outbreak [50] and a computerassisted resilience training consisting of interactive reflective exercises [51]. 
During the disease outbreak Given the likely increase of mental health problems among HCPs, widespread screening to identify those in need of support should be carried out, as the increased stress and burden, as well as stigma experienced by HCPs may make it hard for them to actively seek help [35]. Based on the evidence of risk factors, the following groups may be in particular need of psychological support: HCPs having direct contact with infected patients [6], those that are involuntary deployed to work with infected patients [6], those with less healthcare work experience $[5,32]$, individuals who are single, or do not currently live with family [12, 25], of younger age [5,32], and those with a lower household income [5]. Comparing different groups of HCPs, those who spent time in quarantine should be prioritized $[6$, 25].

A widespread educational campaign alerting HCPs to the possibility of experiencing mental health problems may also help to make those in need come forward for help, as well as fight the potential stigma often associated with mental health problems [35]. Assessment of a wide range of mental health outcomes and psychological distress linked to the disease outbreak [6] is recommended, particularly symptoms of insomnia, alcohol/ drug misuse, PTSD, depression, anxiety, burnout, anger, and perceived stress [5, 32, 33]. For those reporting mental health problems, a three-phased stepped intervention consisting of a workshop on psychological first aid, a workshop on psychoeducation, and a brief CBT group program may be helpful [53]. In order to increase access, this intervention could be carried out by generic healthcare professionals (peers) trained by mental health specialists [53].

With regards to organizational factors, managers should increase organizational support and foster peer support [6]. HCPs should be encouraged to volunteer for working with infected patients [6], rather than be deployed. Managers should regularly provide updated information about the epidemic/pandemic and how HCPs can best protect themselves [6]. Adequate specialized training should be made available $[6,32]$, with personal infection control as a priority $[6,9]$.

After the disease outbreak HCPs' perceived risk should be screened within a few months after the disease outbreak, as this is a risk factor for mental health and occupational problems over 1 year after the outbreak [32].

\section{Discussion}

By conducting this rapid review, we have brought together into one place: the evidence on the impact of pandemics/epidemics on the mental health of HCPs, the evidence of influencing factors on the impact pandemics/epidemics on the mental health of HCPs, and evidence on prevention/interventions to mitigate this impact. Furthermore, we have updated a previous review [5] and broadened the set of mental health outcomes. We bring an additional 10 primary studies beyond those found in the systematic reviews and an additional three papers on interventions. Previously, evidence on social and organizational risk factors had been synthesized [6] and this rapid review adds evidence on psychological and personal risk factors.

Results from this rapid review suggest that HCPs may experience an adverse impact on their mental health during an outbreak, and in the short and long term. However, there remain questions about what consequences the impact on HCPs' mental health will have on levels broader than the individual. Firstly, it seems likely that the mental health issues evidenced here would impact patient care. However, what is not clear from the evidence available so far is whether there is something unique about an epidemic/pandemic that would compromise professional functioning, including patient care, or whether this is due to a more general impact of mental health problems in professionals (that also occurs outside the context of an epidemic/pandemic). Secondly, there may be costs at the organizational and societal levels, as HCPs suffering from the psychological impact of the epidemic/pandemic struggle to maintain their previous working hours, thus affecting staffing levels within the health system [32] and patient care [29]. What none of the reviewed studies sufficiently addresses is the issue that part of the challenge for HCPs is the increased professional demand at a time when both family stress and personal threat (to health) are also elevated.

This rapid review makes recommendations to reduce the negative impact on HCPs' mental health from the evidence of risk and protective factors. However, there remains a lack of evidence-based interventions/preventions that can be recommended for implementation with confidence. Evaluation of these recommendations as part of their implementation would assist future preparations for disease outbreaks to reduce and prevent the impact on the mental health of HCPs.

When considering the findings and recommendations of this rapid review, several elements should be noted. The majority of the evidence from accepted primary studies is heavily reliant on cross-sectional studies assessing self-reported symptoms. No accepted study used a longitudinal design with diagnostics. While it is appreciated that this type of data is collected rapidly in a reactive fashion, researchers should consider the importance of gathering high-quality evidence of true prevalence and risk factors. There were not enough studies or details within these studies to distinguish between specific professional groups or health contexts. Consequently, we took a broad-brush approach across professions 
and contexts when reporting our findings. Furthermore, not all studies had a control group of a nonexposed group but only reported prevalence's during an epidemic/pandemic. We could also consider if the risk and protective factors for HCPs identified here may apply to other key worker professions currently at risk of contact with infected members of the public e.g., teachers.

Moreover, most of the studies were conducted in Asian countries, with only two coming from Europe, eight from Canada/USA, and four from Africa. It is likely that cultural differences between these countries are associated with different nuances in the expression of psychological outcomes. Currently, studies/reviews are being published on a daily basis related to COVID19 and by the time of publication, there will likely be a small body of papers that we were not able to include. Finally, we would like to acknowledge that solid evidence and practice guidelines about psychosocial interventions following other large-scale disasters exist, although they do not specifically target HCPs, e.g.,B Juen, R Warger, S Nindl, H Siller, MJ Lindenthal, E Huttner and S Thormar [56]. However, it is still unknown to what extent these would also be effective in response to an epidemic/ pandemic and future research should investigate whether the mental health impact of (and therefore the intervention required following) an epidemic/pandemic is unique or comparable to that of other large-scale disasters.

A rapid review has some limitations [7], as discussed above. The number of databases searched, languages included, and dates searched were limited. No qualitative studies or grey literature (unpublished or noncommercial material e.g., policy statements or government reports) was included, which may have created a potential (publication) bias. Strengths of the study included strict inclusion/exclusion criteria and only accepted peer-reviewed studies that used validated measures of mental health. Further strengths of this review are that the search terms and strategies were developed in collaboration with specialist librarians and that hand searches of references from accepted full texts were conducted. Additionally, was that multiple researchers cross-checked data extraction to reinforce rigor of the extraction procedures.

\section{Conclusion}

Healthcare professionals exposed to working with patients during an epidemic/pandemic are at heightened risk of mental health problems in the short and longer term. These mental health problems may interfere with the quality of patient care, although further evidence is needed. Healthcare staff need to be provided with psychosocial support to protect their mental wellbeing if they are to continue to provide high quality patient care. Few evidence-based prevention or early intervention programs exist so far. Several recommendations based on risk and protective factors of this review, as well as on additional primary studies are proposed.

\section{Supplementary information}

Supplementary information accompanies this paper at https://doi.org/10. 1186/s12889-020-09322-z.

Additional file 1: Appendix 1. Search Strategies.

\section{Abbreviations}

HCPs: Healthcare professionals; PTSD: Posttraumatic stress disorder; COVID19: Coronavirus disease 2019; SARS: Severe acute respiratory syndrome; MERS: Middle East respiratory syndrome; H1N1: Influenza pandemic; H5N1: Avian influenza; CBT: Cognitive behavioral therapy

\section{Acknowledgments}

We would like to thank Yves Frote for stimulating and discussing this review project with us.

\section{Authors' contributions}

CJ, JE, SS, AH, CD and VS designed the research strategy. The literature search was carried out by JE, CJ, VS and CTS. CD, CTS, AH and VS did the paper screening and data extraction. CTS, CD, VS and SS did the data checking. SS, AH, VS and CD drafted the manuscript. All authors critically revised the manuscript and approved the final version of the manuscript.

\section{Funding}

No funding was provided for this work but CD and VS are currently supported by the Swiss National Science Foundation (grant number 32003B_172982/1; PI: Antje Horsch). AH is a management committee member of COST action CA18211.

\section{Availability of data and materials}

The selection of papers and data used to conduct this rapid review will be made available by the authors on request.

Ethics approval and consent to participate Not applicable.

\section{Consent for publication}

Not applicable.

\section{Competing interests}

The authors declare that the research was conducted in the absence of any commercial or financial relationships that could be construed as a potential conflict of interest.

\section{Author details}

${ }^{1}$ Institute of Higher Education and Research in Healthcare (IUFRS), University of Lausanne, Route de la Corniche 10, 1010 Lausanne, Switzerland. ${ }^{2}$ Medical Library, Lausanne University Hospital and University of Lausanne, Rue du Bugnon 46, 1011 Lausanne, Switzerland. '3Department Woman-Mother-Child, Lausanne University Hospital, Avenue Pierre-Decker 2, 1011 Lausanne, Switzerland.

Received: 18 May 2020 Accepted: 30 July 2020

Published online: 12 August 2020

\section{References}

1. Kunin M, Engelhard D, Piterman L, Thomas S. Response of general practitioners to infectious disease public health crises: an integrative systematic review of the literature. Disaster Med Public Health Prep. 2013; 7(5):522-33.

2. Green MS, Swartz T, Mayshar E, Lev B, Leventhal A, Slater PE, Shemer J. When is an epidemic an epidemic? Isr Med Assoc J. 2002;4(1):3-6. 
3. Morens DM, Folkers GK, Fauci AS. What is a pandemic? I Infect Dis. 2009; 200(7):1018-21.

4. Maunder RG. Was SARS a mental health catastrophe? Gen Hosp Psychiatry. 2009;31(4):316-7.

5. Vyas K, Delaney EM, Webb-Murphy JA, Johnston SL. Psychological impact of deploying in support of the US response to Ebola: a systematic review and meta-analysis of past outbreaks. Mil Med. 2016;181(11):E1515-31.

6. Brooks SK, Dunn R, Amlôt R, Rubin GJ, Greenberg N. A systematic, thematic review of social and occupational factors associated with psychological outcomes in healthcare employees during an infectious disease outbreak. J Occup Environ Med. 2018;60(3):248-57.

7. Garritty C, Gartlehner G, Kamel C, King V, Nussbaumer-Streit B, Stevens A, Hamel C, Affengruber L. Cochrane rapid reviews: Interim Guidance from the Cochrane Rapid Reviews Methods Group; 2020.

8. Chan AO, Huak CY. Psychological impact of the 2003 severe acute respiratory syndrome outbreak on health care workers in a medium size regional general hospital in Singapore. Occup Med (Lond). 2004;54(3):190-6.

9. Chan SS, Leung GM, Tiwari AF, Salili F, Leung SS, Wong DC, Wong AS, Lai AS, Lam TH. The impact of work-related risk on nurses during the SARS outbreak in Hong Kong. Fam Community Health. 2005;28(3):274-87.

10. Chen CS, Wu HY, Yang P, Yen CF. Psychological distress of nurses in Taiwan who worked during the outbreak of SARS. Psychiatr Serv. 2005;56(1):76-9.

11. Chen NH, Wang PC, Hsieh MJ, Huang CC, Kao KC, Chen YH, Tsai YH. Impact of severe acute respiratory syndrome care on the general health status of healthcare workers in Taiwan. Infect Control Hosp Epidemiol. 2007;28(1):75-9.

12. Chong MY, Wang WC, Hsieh WC, Lee CY, Chiu NM, Yeh WC, Huang OL, Wen JK, Chen CL. Psychological impact of severe acute respiratory syndrome on health workers in a tertiary hospital. Br J Psychiatry. 2004;185: 127-33.

13. Chua SE, Cheung V, Cheung C, MCAlonan GM, Wong JW, Cheung EP, Chan MT, Wong MM, Tang SW, Choy KM, et al. Psychological effects of the SARS outbreak in Hong Kong on high-risk health care workers. Can J Psychiatr. 2004;49(6):391-3.

14. Fiksenbaum L, Marjanovic Z, Greenglass ER, Coffey S. Emotional exhaustion and state anger in nurses who worked during the sars outbreak: the role of perceived threat and organizational support. Can I Community Ment Health. 2006;25(2):89-103.

15. Goulia P, Mantas C, Dimitroula D, Mantis D, Hyphantis T. General hospital staff worries, perceived sufficiency of information and associated psychological distress during the a/H1N1 influenza pandemic. BMC Infect Dis. 2010;10:322

16. Ji D, Ji YJ, Duan XZ, Li WG, Sun ZQ, Song XA, Meng YH, Tang HM, Chu F, Niu XX, et al. Prevalence of psychological symptoms among Ebola survivors and healthcare workers during the 2014-2015 Ebola outbreak in Sierra Leone: a cross-sectional study. Oncotarget. 2017:8(8):12784-91.

17. Kim JS, Choi JS. Factors influencing emergency Nurses' burnout during an outbreak of Middle East respiratory syndrome coronavirus in Korea. Asian Nurs Res (Korean Soc Nurs Sci). 2016;10(4):295-9.

18. Koh D, Lim MK, Chia SE, Ko SM, Qian F, Ng V, Tan BH, Wong KS, Chew WM, Tang HK, et al. Risk perception and impact of severe acute respiratory syndrome (SARS) on work and personal lives of healthcare workers in Singapore: what can we learn? Med Care. 2005;43(7):676-82.

19. Lancee WJ, Maunder RG, Goldbloom DS. Prevalence of psychiatric disorders among Toronto hospital workers one to two years after the SARS outbreak. Psychiatr Serv. 2008:59(1):91-5.

20. Lee AM, Wong JGS, MCAlonan GM, Cheung V, Cheung C, Sham PC, Chu CM, Wong PC, Tsang KWT, Chua SE. Stress and psychological distress among SARS survivors 1 year after the outbreak. Can J Psychiatr. 2007;52(4):233-40.

21. Lee SM, Kang WS, Cho AR, Kim T, Park JK. Psychological impact of the 2015 MERS outbreak on hospital workers and quarantined hemodialysis patients. Compr Psychiatry. 2018(87):123-7.

22. Lehmann M, Bruenahl CA, Addo MM, Becker S, Schmiedel S, Lohse AW, Schramm C, Löwe B. Acute Ebola virus disease patient treatment and health-related quality of life in health care professionals: a controlled study. J Psychosom Res. 2016;83:69-74.

23. Li L, Wan C, Ding R, Liu Y, Chen J, Wu Z, Liang C, He Z, Li C. Mental distress among Liberian medical staff working at the China Ebola treatment unit: a cross sectional study. Health Qual Life Outcomes. 2015;13:156.

24. Lin CY, Peng YC, Wu YH, Chang J, Chan CH, Yang DY. The psychological effect of severe acute respiratory syndrome on emergency department staff. Emerg Med J. 2007;24(1):12-7.
25. Liu X, Kakade M, Fuller CJ, Fan B, Fang Y, Kong J, Guan Z, Wu P. Depression after exposure to stressful events: lessons learned from the severe acute respiratory syndrome epidemic. Compr Psychiatry. 2012;53(1):15-23.

26. Lu YC, Shu BC, Chang YY, Lung FW. The mental health of hospital workers dealing with severe acute respiratory syndrome. Psychother Psychosom. 2006;75(6):370-5.

27. Lung FW, Lu YC, Chang YY, Shu BC. Mental symptoms in different health professionals during the SARS attack: a follow-up study. Psychiatr Q. 2009; 80(2):107-16.

28. Mak IWC, Chu CM, Pan PC, Yiu MGC, Chan VL. Long-term psychiatric morbidities among SARS survivors. Gen Hosp Psychiatry. 2009;31(4):318-26.

29. Marjanovic Z, Greenglass ER, Coffey S. The relevance of psychosocial variables and working conditions in predicting nurses' coping strategies during the SARS crisis: an online questionnaire survey. Int J Nurs Stud. 2007:44(6):991-8.

30. Matsuishi K, Kawazoe A, Imai H, Ito A, Mouri K, Kitamura N, Miyake K, Mino K, Isobe M, Takamiya S, et al. Psychological impact of the pandemic (H1N1) 2009 on general hospital workers in Kobe. Psychiatry Clin Neurosci. 2012; 66(4):353-60.

31. Maunder R. The experience of the 2003 SARS outbreak as a traumatic stress among frontline healthcare workers in Toronto: lessons learned. Philos Trans R Soc Lond Ser B Biol Sci. 2004;359(1447):1117-25.

32. Maunder RG, Lancee WJ, Balderson KE, Bennett JP, Borgundvaag B, Evans S, Fernandes CM, Goldbloom DS, Gupta M, Hunter JJ, et al. Long-term psychological and occupational effects of providing hospital healthcare during SARS outbreak. Emerg Infect Dis. 2006;12(12):1924-32.

33. MCAlonan GM, Lee AM, Cheung V, Cheung C, Tsang KW, Sham PC, Chua SE, Wong JG. Immediate and sustained psychological impact of an emerging infectious disease outbreak on health care workers. Can J Psychiatr. 2007; 52(4):241-7.

34. Nickell LA, Crighton EJ, Tracy CS, Al-Enazy H, Bolaji Y, Hanjrah S, Hussain A, Makhlouf S, Upshur RE. Psychosocial effects of SARS on hospital staff: survey of a large tertiary care institution. Cmaj. 2004;170(5):793-8.

35. Park JS, Lee EH, Park NR, Choi YH. Mental health of nurses working at a government-designated hospital during a MERS-CoV outbreak: a crosssectional study. Arch Psychiatr Nurs. 2018;32(1):2-6.

36. Phua DH, Tang HK, Tham KY. Coping responses of emergency physicians and nurses to the 2003 severe acute respiratory syndrome outbreak. Acad Emerg Med. 2005;12(4):322-8.

37. Poon E, Liu KS, Cheong DL, Lee CK, Yam LY, Tang WN. Impact of severe respiratory syndrome on anxiety levels of front-line health care workers. Hong Kong Med J. 2004;10(5):325-30.

38. Sim K, Chong PN, Chan YH, Soon WS. Severe acute respiratory syndromerelated psychiatric and posttraumatic morbidities and coping responses in medical staff within a primary health care setting in Singapore. J Clin Psychiatry. 2004;65(8):1120-7.

39. Son H, Lee WJ, Kim HS, Lee KS, You M. Hospital workers' psychological resilience after the 2015 Middle East respiratory syndrome outbreak. Soc Behav Personal Int J. 2019;47(2):1-13.

40. Styra R, Hawryluck L, Robinson S, Kasapinovic S, Fones C, Gold WL. Impact on health care workers employed in high-risk areas during the Toronto SARS outbreak. J Psychosom Res. 2008:64(2):177-83.

41. Su T-P, Lien TC, Yang CY, Su YL, Wang JH, Tsai SL, Yin JC. Prevalence of psychiatric morbidity and psychological adaptation of the nurses in a structured SARS caring unit during outbreak: a prospective and periodic assessment study in Taiwan. J Psychiatr Res. 2007:41(1):119-30.

42. Sun H, Ren X. Psychological analysis for the medical staff suffering from severe acute respiratory syndrome. Chin J Clin Rehabil. 2004;8(33):7609-11.

43. Tam CW, Pang EP, Lam LC, Chiu HF. Severe acute respiratory syndrome (SARS) in Hong Kong in 2003: stress and psychological impact among frontline healthcare workers. Psychol Med. 2004;34(7):1197-204.

44. Tham KY, Tan YH, Loh OH, Tan WL, Ong MK, Tang HK. Psychiatric morbidity among emergency department doctors and nurses after the SARS outbreak. Ann Acad Med Singap. 2004;33(5):S78-9.

45. Verma S, Mythily S, Chan YH, Deslypere JP, Teo EK, Chong SA. Post-SARS psychological morbidity and stigma among general practitioners and traditional Chinese medicine practitioners in Singapore. Ann Acad Med Singapore. 2004;33(6):743-8.

46. Wong TW, Yau JK, Chan CL, Kwong RS, Ho SM, Lau CC, Lau FL, Lit CH. The psychological impact of severe acute respiratory syndrome outbreak on healthcare workers in emergency departments and how they cope. Eur J Emerg Med. 2005;12(1):13-8. 
47. Wu P, Fang Y, Guan Z, Fan B, Kong J, Yao Z, Liu X, Fuller CJ, Susser E, Lu J, et al. The psychological impact of the SARS epidemic on hospital employees in China: exposure, risk perception, and altruistic acceptance of risk. Can J Psychiatr. 2009;54(5):302-11.

48. Xiao $H$, Zhang $Y$, Kong D, Li S, Yang N. The effects of social support on sleep quality of medical staff treating patients with coronavirus disease 2019 (COVID-19) in January and February 2020 in China. Med Sci Monit. 2020;26:e923549.

49. Chen R, Chou KR, Huang YJ, Wang TS, Liu SY, Ho LY. Effects of a SARS prevention programme in Taiwan on nursing staff's anxiety, depression and sleep quality: a longitudinal survey. Int J Nurs Stud. 2006;43(2):215-25.

50. Marrs R, Horsley TL, Hackbarth D, Landon E. High consequence infectious diseases training using interprofessional simulation and TeamSTEPPS. Am J Infect Control. 2019;48(6).

51. Maunder RG, Lancee WJ, Mae R, Vincent L, Peladeau N, Beduz MA, Hunter $\mathrm{JJ}$, Leszcz M. Computer-assisted resilience training to prepare healthcare workers for pandemic influenza: a randomized trial of the optimal dose of training. BMC Health Serv Res. 2010;10:72.

52. Sijbrandij M, Horn R, Esliker R, O'may F, Reiffers R, Ruttenberg L, Stam K, de Jong J, Ager A. The effect of psychological first aid training on knowledge and understanding about psychosocial support principles: A clusterrandomized controlled trial. Int J Environ Res Public Health. 2020;17(2):48495.

53. Waterman $\mathrm{S}$, Hunter ECM, Cole $\mathrm{CL}$, Evans $L$, Greenberg N, Rubin GJ, Beck A. Training peers to treat Ebola Centre workers with anxiety and depression in Sierra Leone. Int J Soc Psychiatry. 2018;64(2):156-65.

54. Gardner PJ, Moallef P. Psychological impact on SARS survivors: critical review of the English language literature. Can Psychol/Psychol Can. 2015; 56(1):123-35.

55. Wong EL, Wong SY, Kung K, Cheung AW, Gao TT, Griffiths S. Will the community nurse continue to function during H1N1 influenza pandemic: a cross-sectional study of Hong Kong community nurses? BMC Health Serv Res. 2010;10:107.

56. Juen B, Warger R, Nindl S, Siller H, Lindenthal MJ, Huttner E, Thormar S. The comprehensive guideline on mental health and psychosocial support (MHPSS) in disaster settings. Innsbruck: OPSIC; 2016.

\section{Publisher's Note}

Springer Nature remains neutral with regard to jurisdictional claims in published maps and institutional affiliations.

Ready to submit your research? Choose BMC and benefit from:

- fast, convenient online submission

- thorough peer review by experienced researchers in your field

- rapid publication on acceptance

- support for research data, including large and complex data types

- gold Open Access which fosters wider collaboration and increased citations

- maximum visibility for your research: over $100 \mathrm{M}$ website views per year

At BMC, research is always in progress.

Learn more biomedcentral.com/submissions 